Hellmers, Sandra; Manojlovic, Natasa; Palmaricciotti, Giovanni; Fröhle, Peter Modelling Decentralised Systems for Urban Drainage and Flood Mitigation

Zur Verfügung gestellt in Kooperation mit / Provided in Cooperation with:

Kuratorium für Forschung im Küsteningenieurwesen (KFKI)

Verfügbar unter / Available at:

https://hdl.handle.net/20.500.11970/99453

Vorgeschlagene Zitierweise / Suggested citation:

Hellmers, Sandra; Manojlovic, Natasa; Palmaricciotti, Giovanni; Fröhle, Peter (2014): Modelling Decentralised Systems for Urban Drainage and Flood Mitigation. In: Lehfeldt, Rainer; Kopmann, Rebekka (Hg.): ICHE 2014. Proceedings of the 11th International Conference on Hydroscience \& Engineering, September 28 - October 2, 2014, Hamburg, Germany. Karlsruhe: Bundesanstalt für Wasserbau. S. 375-384.

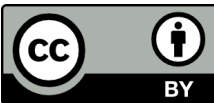




\title{
Modelling Decentralised Systems for Urban Drainage and Flood Mitigation
}

\author{
S. Hellmers, N. Manojlovic, G. Palmaricciotti \& P. Fröhle \\ Institute of River and Coastal Engineering, Hamburg University of Technology, Hamburg, Germany
}

\begin{abstract}
Assessing the performance of future urban drainage management practices requires novel hydrological modelling approaches that can handle a large number of spatially distributed measures, such as Sustaina-ble Drainage Systems (SUDS). This paper presents the implementation of a SUDS modelling approach in a semi-distributed hydrological model that enables the simulation of flow between multiple linked SUDS and meso-scale retention spaces and the application of this model to an urban catchment. Combination of local drainage systems and water retention in public spaces may provide an appropriate strategy to cope with present and future pressures on the urban drainage infrastructure. The objectives of the implemented model are the representation of SUDS as model elements with water re-distribution functionality as well as its integration into a flood management tool. The model was applied to quantify the impacts of socio-economic and climate change in an urban catchment in Hamburg, Germany, under different future scenar-ios and combinations of SUDS. The results demonstrate the potential of SUDS and multipurpose reten-tion spaces for flood peak mitigation.
\end{abstract}

Keywords: SUDS, Urban Drainage, Decentralised Systems, Flood Mitigation, Climate Change Impact

\section{INTRODUCTION}

Drainage infrastructures in urban areas prevent frequent flooding and protect water courses from combined sewage and stormwater runoff. Adaptive strategies are required to manage uncertainties of the future development mainly caused by climate change (IPCC 2012) or rapid urbanisation (UN 2011). Here, decentralised strategies (referred to as SUDS) gain a growing importance in recent years, due to its positive effects on water quality and quantity and additionally their adaptive or multifunctional nature (e.g. Wong et al. 2013, Zhou 2014). These measures treat or drain water in a more sustainable way by activating its natural behaviours and processes in the urban environment using infiltration, retention and storage (Zhou 2014). These measures consist of (mostly vegetated) source-control structures such as swales or green roofs, with a limited capacity and a specific design threshold. In case of storm events that surpass the capacity of SUDS, the control of exceedance flow is of particular concern. If the design value of an element (e.g. green roof) is exceeded, the "overflow" can be conveyed by roads or streets to a multipurpose area (e.g. a park or open green space). By linking those measures into a cascade of measures, an integrated system can be created.

The recent progress in sustainable drainage development is dealt with in literature across different disciplinary fields (e.g. Stovin et al. 2013, Wong et al. 2013, Zhou 2014). However, a research need is seen in quantifying the hydrologic performance of those cascades of individual SUDS measures and their performance on site scale as well as on catchment scale (Stovin et. al. 2013). A range of available modelling tools allow the simulation of SUDS (e.g. MIKE-SWMM, QQS, STORM, SWMM, MUSIC) for different purposes and applications. Elliott and Trowsdale (2007) compared 10 models with regard to their capability and relevance to sustainable drainage systems. The selection of the most suitable model is mainly driven by the purpose (planning or design), the spatial scale of the modelling analysis (site scale or catchment scale) or by the type of SUDS elements to be modelled (Velasco et al. 2013). Another aspect is the availability and usability of the model. Commercial models support (more or less) the usability, but 
their costs are often high and the availability is limited. In contrast open-source models require only nominal costs, but the user may need more technical knowledge to apply the model.

The objective of this paper is to describe a new approach enabling the detailed hydrological modelling of these drainage management strategies and its implementation into the open-source semi-distributed hydrologic model KalypsoHydrology. The tool has been applied to assess the performance of small-scale SUDS measures and multipurpose spaces at the example of the Wandse catchment in the city of Hamburg, Germany. In the case study, the impacts of future land use and climate change scenarios on the peak discharge and inundated areas are quantified. The results will be presented and the conclusions drawn.

\section{METHODOLOGY}

The design and implementation of SUDS and multipurpose spaces in urban areas depends on local features of the landuse. The distribution of green roofs depends on the availability of building shapes, whereas the distribution of retention spaces and infiltration measures depends on the availability of free spaces. This demands for a modelling approach which can handle a large number of spatially distributed measures and a sufficiently detailed land use map is now required matching the spatial detail of the SUDS distribution in the model area. Semi distributed hydrologic models (SDHM) allow the simulation of the entire land-based part of the water balance on the basis of given precipitation time series. The catchment is divided into hydrotops (a.k.a. hydrologic response units), i.e. units with distinguished land use, drainage and soil characteristics, for which the water balance is performed. However, in SDHM the defined landuse units are composed of heterogeneous elements. For example the landuse class "detached buildings" contains both, a building and a green space. In the case that different SUDS elements are to be applied, this differentiation has to be made as green roofs and swales can be applied only on buildings or green spaces respectively.

\subsection{Theoretical Approach - Integration of SUDS into hydrologic modelling by overlays}

In order to take into account the effects of SUDS, the existing data model of hydrotops in a SDHM should be redefined by integrating a differentiated description of the SUDS elements. Firstly, those SUDS elements should be spatially distributed to be in accordance with the given landuse data as shown in Figure 1. The green roofs are for instance allocated on the existing or planned buildings, whereby the distribution of retention spaces is depending on the availability of free space. The additional information of SUDS and retention areas is represented in the form of "overlays". Overlays are data sets and contain the parameters about the drainage functionality and the materials in SUDS. The new, redefined, hydrotops are finally created by geometrically intersecting the land use, soil type, watershed and overlays. The main parameters are outlined in Figure 1.

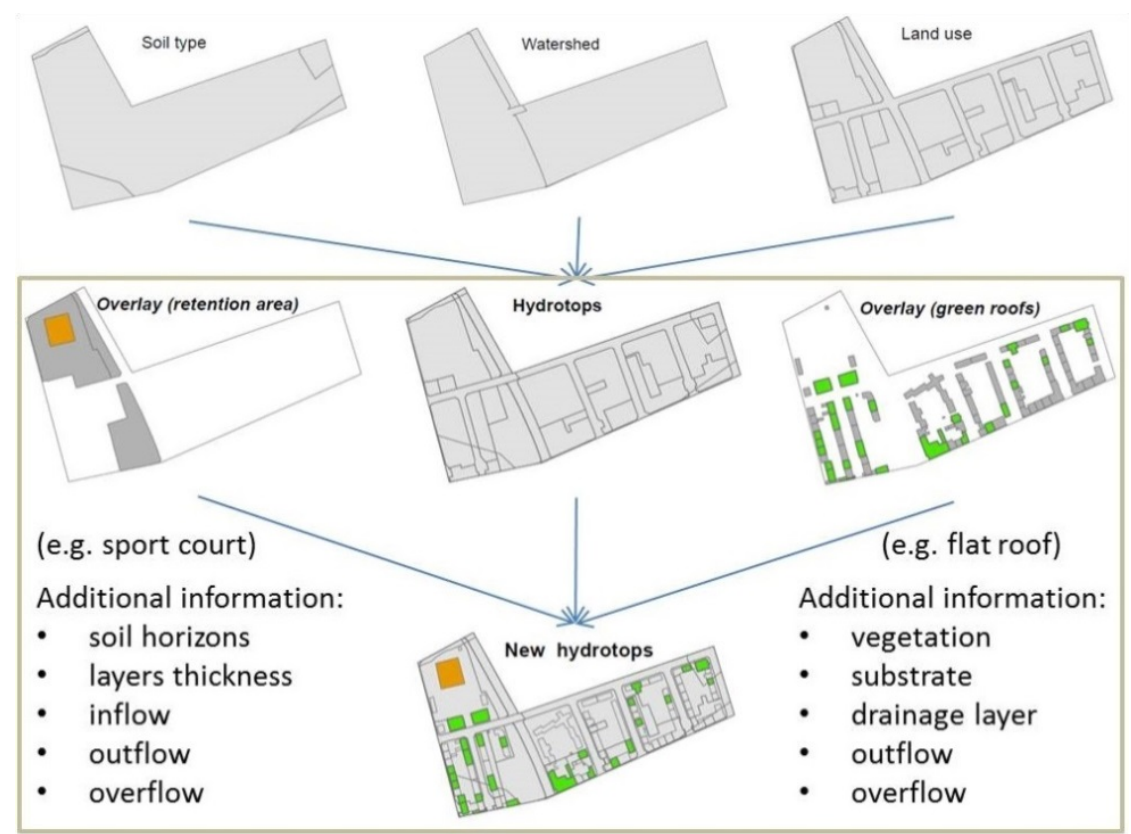

Figure 1. Spatial intersection and aggregation define equal hydrological response units (hydrotops). The new hydrotops contain the SUDS information in the overlay data sets 
Secondly, in order to simulate the physical processes in the individual SUDS elements for the modelling purpose, these elements are subdivided into a sequence of vertical layers which are defined based on their characteristics and functionality as shown in Figure 2. The parameters of the vertical layers of different SUDS are assigned to the corresponding units (i.e. green roofs, swales or swale-filter-drain-systems) in the redefined hydrotops and feeded into the model. A detailed description of the modelling procedure and parameters of the individual measures is given in the previous work of the author (Hellmers 2010).
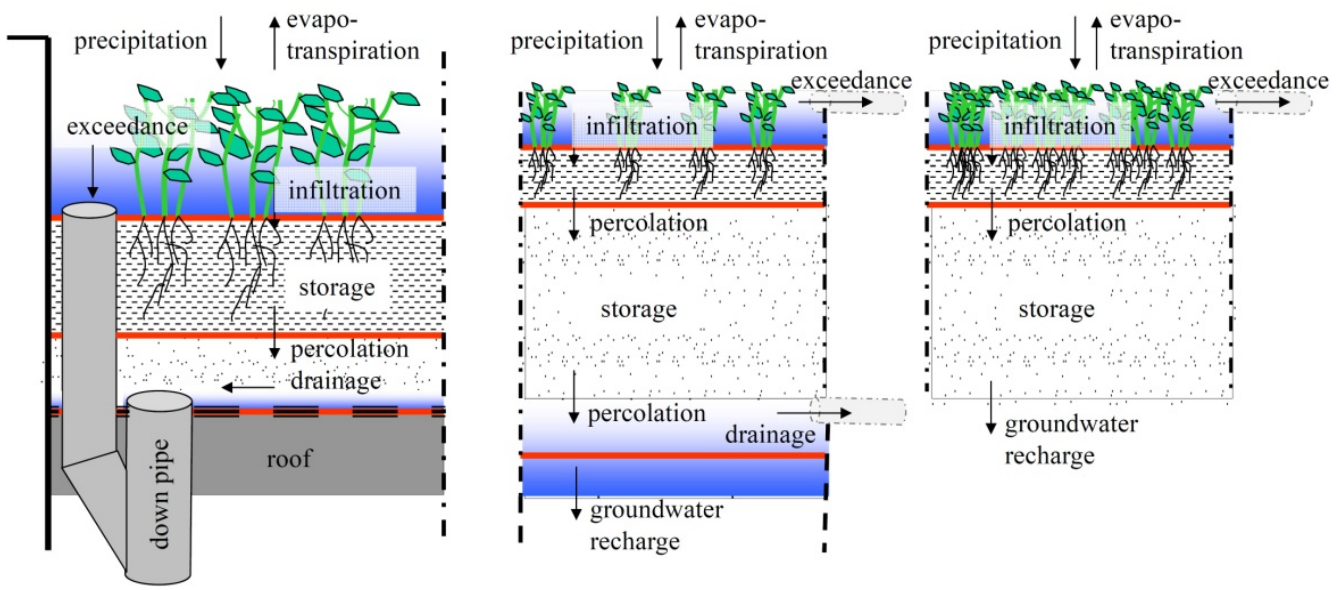

Figure 2. Schematic design of SUDS: green roof (left), swale-filter-drain-system (middle), swale (right) (adopted from Hellmers 2010)

\subsection{Implementation of overlays in the system plan}

KalypsoHydrology, an open-source SDHM for the simulation of the land-based water balances in river catchments (Pasche 2003), has been enhanced to include the theoretical approach of overlays. The model network in the hydrologic model used to describe the runoff concentration from upstream to downstream sections in a river system consists of sub-catchments, drainage strands and drainage nodes (Figure 3). The enhanced methodology allows the conveyance of exceedance flow in a chain of small-scale SUDS measures and larger-scale retention spaces. For this purpose, the new model accounts for the possibility that a single SUDS measure or designated area may both receive and distribute water. For that purpose, the model network has been enhanced with additional linkages to redistribute water from drainage nodes to areas. The areas with the functionality to drain and receive water are defined in the model as overlays (see Figure 3 "system plan with overlays").

\section{System Plan}

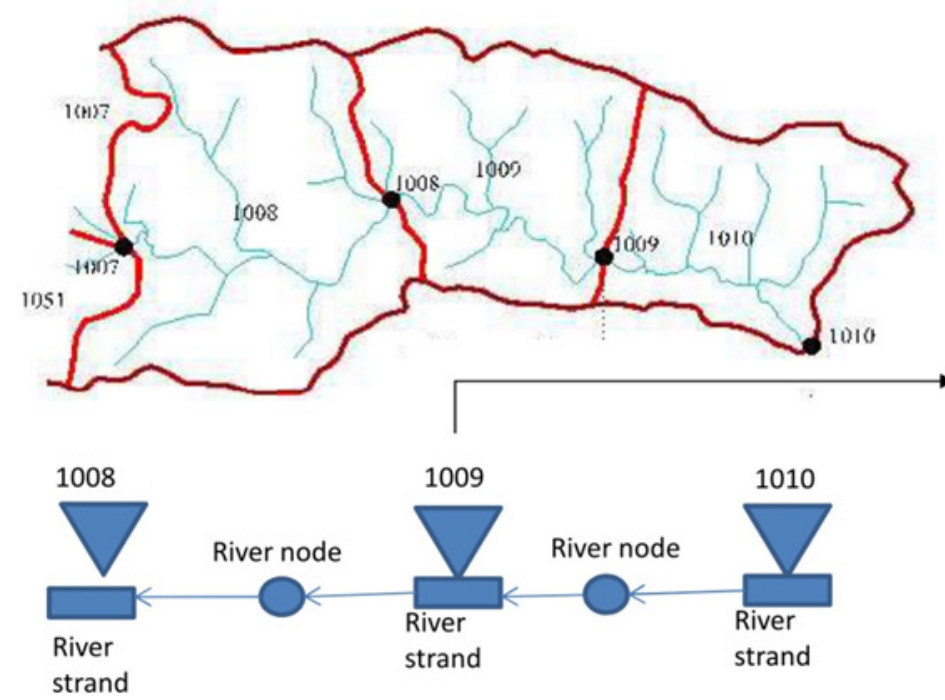

\section{System Plan with Overlays}

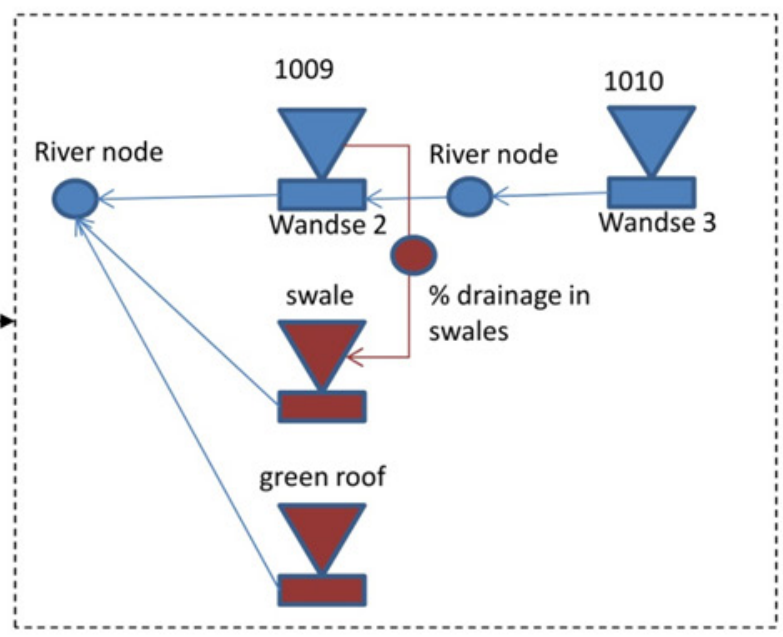

Figure 3. Implementation of overlays in the system plan of a SDHM

During the computation, these areas are transformed into additional drainage subcatchments and an algorithm has been implemented in the model KalypsoHydrology to cross link these subcatchments in the 
overall drainage system with drainage strands and drainage nodes. The partial or entire distribution of water in the model network plan is attributed to drainage nodes. When the design capacity of the elements on properties (e.g. green roofs, swales) is reached by a storm event (P) the exceedance flow is distributed to retention areas in the larger system (e.g. multipurpose spaces, such as a sports field) or to the drainage network (see Figure 4).

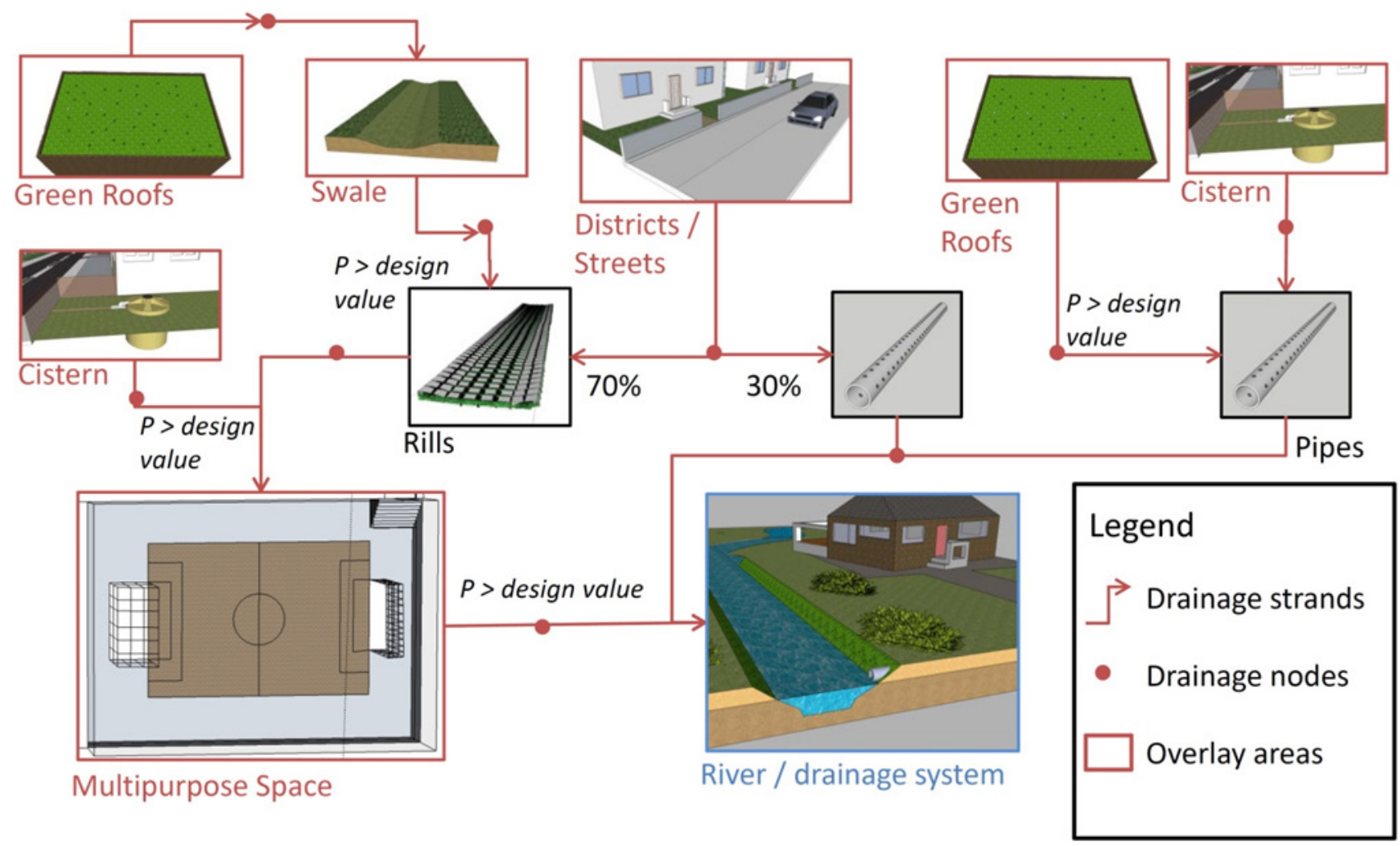

Figure 4. Linkage of small-scale SUDS measures and larger-scale retention spaces (overlay areas)

\subsection{Integration in Urban Drainage and Flood ManagementTool}

The enhanced hydrological model, KalypsoHydrology, is part of the open-source modelling platform Kalypso (http://kalypso.bjoernsen.de). This software tool connects hydrologic and hydrodynamic and risk simulation models for using in flood risk management planning. The data processing in the Kalypso modelling framework is presented in Figure 5. Scenario simulations of future urban development projections can be derived from a calibrated basic model using overlay areas representing adaptation strategies like SUDS or retention areas. Before the computation, the original model network plan is updated with the overlay areas and their interconnections. Climate change projections are imported as continuous time series for long-term water balance and short-term flood peak simulations. In the process chain of Kalypso steady-state non-uniform rivers hydraulics are computed with a one-dimensional water surface profile model (KalypsoWSPM). Additionally, an unsteady and 1D-2D coupled surface flow can be calculated with the module Kalypso1D2D. In the post-processing phase, the inundated areas and flow depths can be computed based on digital terrain data using the module KalypsoFlood. 


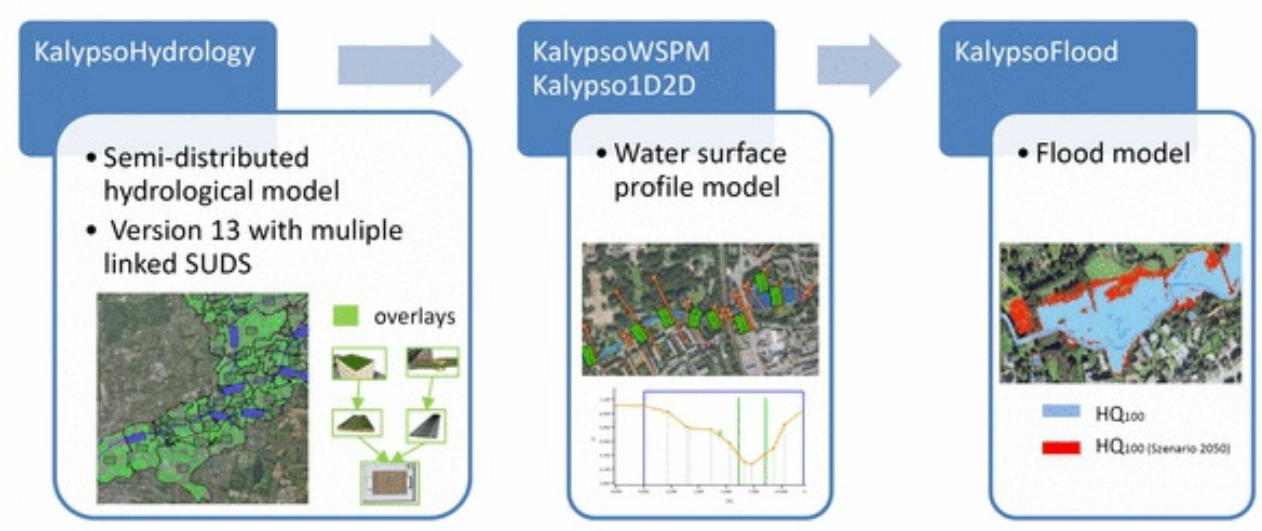

Figure 5. Kalypso modules for urban drainage and flood modelling

\section{APPLICATION}

The enhanced hydrological model has been applied to quantify the impacts of land use and climate change projections for 2050 in the Wandse catchment in Hamburg assuming adaptation strategies with small-scale SUDS measures and larger-scale retention areas. The river Wandse stretches over $21.5 \mathrm{~km}$ and drains a total catchment area of $88 \mathrm{~km}^{2}$. It is a typical small urban catchment with its spring located in rather undeveloped or rural areas. The main part of the area is covered by urbanised areas with high sealing rates and vast modified water bodies. Results of the flood impacts in the study area of the Wandse catchment are illustrated for an "urban", "urban-suburban" and a "suburban" neighbourhood.

\subsection{Climate Change Impacts}

Based on two regional climate model (REMO) runs for the scenario A1B (Jacob et al. 2006 and Jacob et al. 2009), long-term water balance and flood peak events are calculated for a climate period from 2036 to 2065. The used climate data series comprise daily average temperature, sun duration, air humidity and wind speed data in a spatial resolution of $10 \mathrm{~km}^{2}$. One of the main concern is the spatial and temporal distribution of precipitation for urban flood modelling. The regional climate model computes vertically falling daily and hourly precipitation time series for both A1B model runs. Additionally, this data has been post-processed with the information of wind drifted precipitation and the data has been bias-corrected. These three precipitation data sets span a range of six possible future projections. The deviation between the results is illustrated in Figure 6. For events with return periods of 2 or 5 years, an increase of the peak river discharge of up to $27 \%$ and $20 \%$, respectively, has been calculated. For events with return periods of 10 or 30 years, there is no clear evidence of an increase or decrease in flood peak discharge. The largest variance has been found for events with return periods of up to 100 years. Flood peak discharges are computed with up to $20 \%$ increase, but as well with over $30 \%$ decrease. In order to assess the performance of SUDS under negative climate change effects, a high increase of flood peak discharge $(+20 \%)$ has been selected as the basis for subsequent impact studies. 


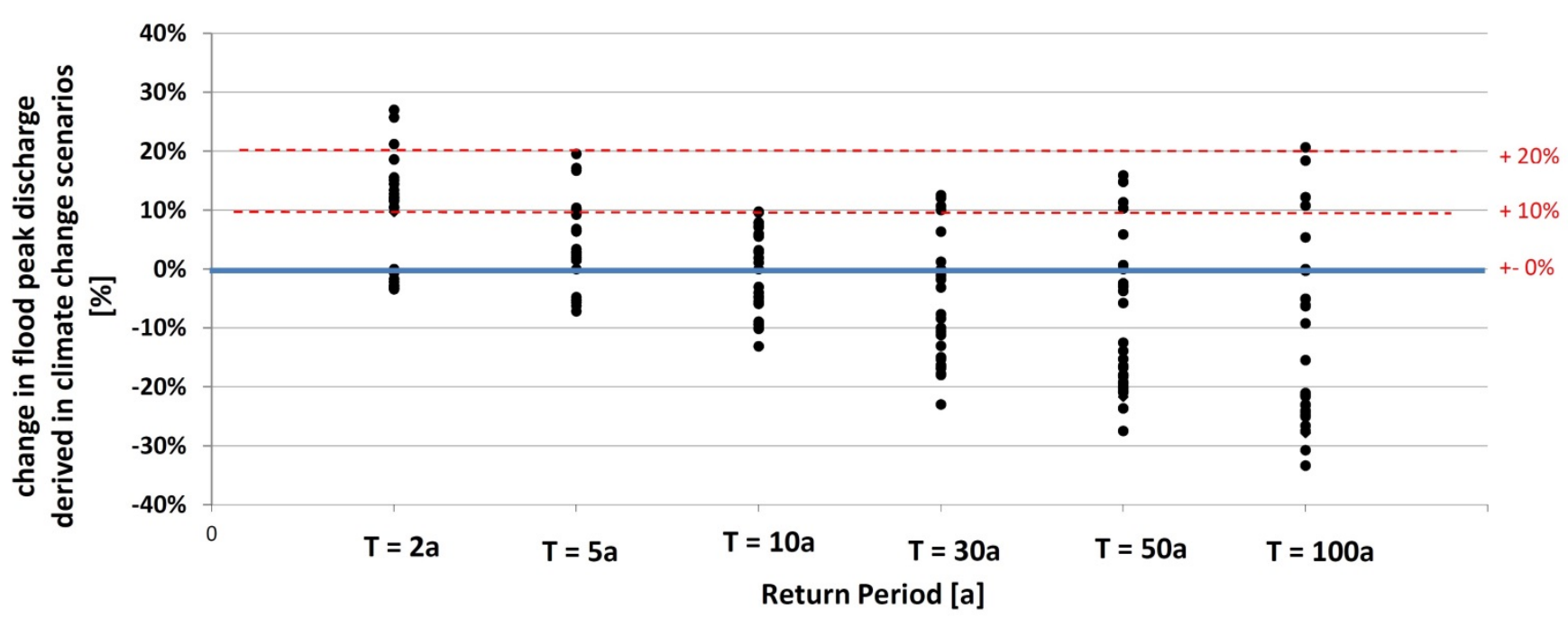

Figure 6. Changes in flood peak discharges of different return periods based on regional climate model (REMO) runs for the climate scenario A1B (2035 - 2065) for the Wandse catchment.

\subsection{Urban Growth and Adaptation Strategies}

In the KLIMZUG-Nord project, socio-economic scenarios for 2050 have been defined with a group of stakeholders in the Wandse catchment (i.a. authorities, spatial planners, ecologists, academia, NGOs) in cooperation with the KLIMZUG-North project (Rottgardt et. al. 2014). The first scenario (S1) assumes a decrease in population in the inner city, which means the people are moving into the suburbs. Because of less financial support, the buildings and infrastructure in the inner city remain more or less the same. In this scenario, no adaptation strategy is applied. The second scenario (S2) assumes an increase of the population in the city of Hamburg. New buildings are constructed and the infrastructure is enlarged. In this scenario, the impervious areas in the city increase, which raises the need for alternative urban drainage systems. In this scenario, a moderate implementation of SUDS measures is assumed to be supported financially. In the third scenario (S3), an increase of inhabitants is assumed, too. But the demand of new living space is assumed to be met by increasing the height of buildings. Impervious areas increase to a lesser extent than in the second scenario. In this scenario, the government heavily subsidises the implementation of adaptation strategies like SUDS (green roofs, swales, swale-filter-drain systems) and larger water retention facilities in the city.

\subsection{Results}

The software module KalypsoHydrology has been applied to develop scenario models on the basis of climate change impact assumptions $(+20 \%$ change in flood peak discharge) and three urban growth assumptions (S1, S2, S3) including adaptation strategies for 2050. Small-scale SUDS and larger-scale retention areas have been defined in the model as overlay areas. The detailed spatial distribution of these areas is illustrated for the socio-economic scenarios in Figure 7.
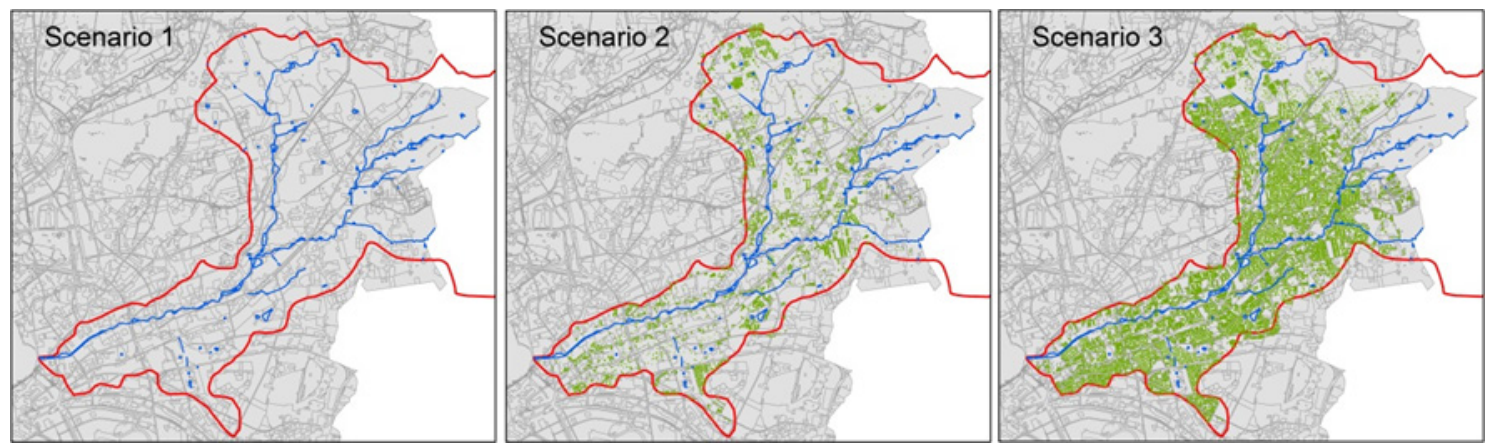

Figure 7. Spatial distribution of decentralized drainage measures in the Wandse catchment for the urban growth scenario S1 (left: no measures), scenario S2 (middle) and S3 (right). 
Based on peak discharges resulting from KalypsoHydrology, the river hydraulics were computed with the one-dimensional water surface profile model KalypsoWSPM. The inundated areas and flow depth were calculated on the basis of digital terrain data with the module KalypsoFlood. The computed inundated areas and water flow depths are illustrated in Figure 8 for an urban area, an urban-suburban area and a suburban area.

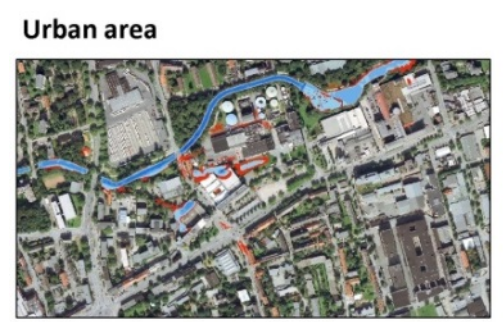

Urban suburban area

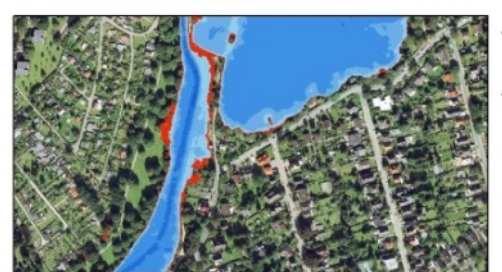

; no adaption measures (Scenario 1)

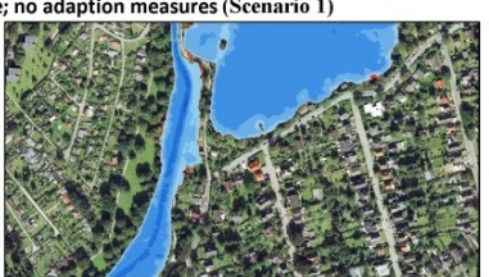

Suburban area
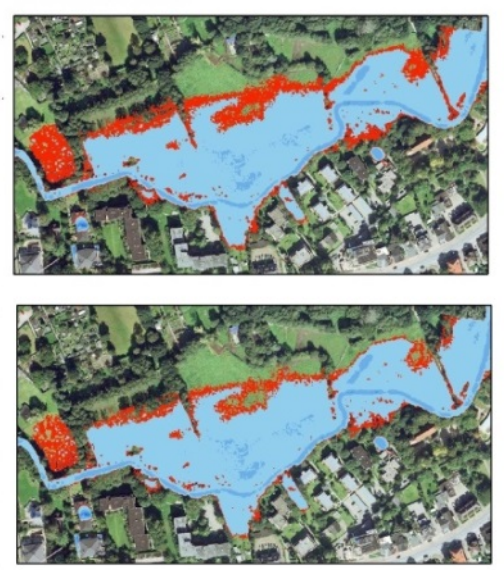

cenario 2)

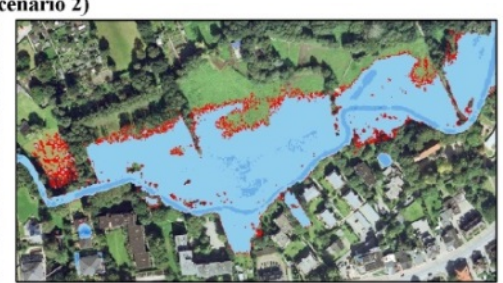

c) climate change impact of $20 \%$ increase in discharge; broad implementation of adaption measures (Scenario 3 )

Legend

\begin{tabular}{|c|c|c|}
\hline \multirow[t]{5}{*}{$\begin{array}{l}\text { less flooding } \\
\text { increased flooding }\end{array}$} & \multicolumn{2}{|c|}{$\begin{array}{l}\text { Reference Flood Event } \mathrm{T}=100 \\
\text { Waterlevel }\end{array}$} \\
\hline & $\square<0,01 \mathrm{~m}$ & $1,50 m-2,00 m$ \\
\hline & $\square 0,01 \mathrm{~m}-0,50 \mathrm{~m}$ & $2,00 m-2,50 m$ \\
\hline & $\square 0,50 m-1,00 m$ & $=2,50 \mathrm{~m}-3,00 \mathrm{~m}$ \\
\hline & $1,00 \mathrm{~m}-1,50 \mathrm{~m}$ & $=3,00 m-3,50 m$ \\
\hline
\end{tabular}

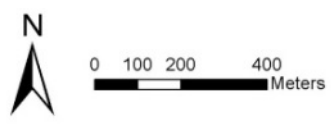

Figure 8. Change in flow depth and inundated areas of a 100 year flood event on the basis of the three land use scenarios $\mathrm{S} 1$ (top), S2 (middle) and S3 (bottom) and a climate change impact of 20\% increase in flood peak discharge. The results are illustrated for a highly urbanised (left), an urban-suburban (middle) and a suburban area (right)

For this catchment, a maximum increase of $20 \%$ in flood peak discharge due to climate change is projected for 2050 (Hellmers \& Hüffmeyer 2014). For the selected urban and urban-suburban areas, minor impacts on the inundated areas of a 100 year flood were calculated for the climate change and urban growth scenarios. This can be explained by the high river banks which prevent flooding of adjacent properties. On the contrary, in the upstream river section, i.e. the suburban area, the river topography is shallow. Here, the increased peak discharges due to climate change and urban growth enlarges the inundated areas. In particular, the northern side of the river is affected. The result in scenario S1 shows the increase of the inundation area by the impacts of climate change and urban growth without measures. By implementing measures in scenario S2 and scenario S3 the impacts of climate change and urban growth on the inundation areas can be mitigated.

\section{CONCLUSION}

The novel hydrological modelling approach enables the detailed computation of a large number of spatially distributed SUDS in urban catchments and the redistribution of exceedance flow to larger-scale water retention areas. The enhanced module is part of the open-source software product Kalypso for flood risk management planning. The model application in the urban area of Hamburg provide a better understanding of the mitigation efficiency that can be reached using strategically placed, appropriate SUDS within an urban catchment. However, the uncertainties in nature and magnitude of climate change projections, urban growth scenarios as well as of impact modelling have to be investigated in a more detailed way to assess future flood risk in urban areas. 


\section{ACKNOWLEDGEMENT}

The work described in this paper was made possible through support by a grant from the German Ministry for Education and Research (Bundesministerium für Bildung und Forschung) as part of its KLIMZUG initiative. The authors gratefully thank for this support.

\section{REFERENCES}

Elliott, A.H. and Trowsdale, S.A. (2007) A review of models for low impact urban stormwater drainage. Environmental Modelling \& Software, 22, 394-405.

Hellmers, S. (2010) Hydrological Impacts of Climate Change on Flood Probability in Small Urban Catchments and Possibilities of Flood Risk Mitigation. Hamburger Wasserbau-Schriften 13. Master's thesis, Institute of River and Coastal Engineering, Hamburg University of Technology, Hamburg.

Hellmers, S. and Hüffmeyer, N. (2014) Folgen für Kanalnetz und Gewässer. In: Kruse, E., Zimmermann, T., Kittel, A., Dickhaut, W., Knieling, J., Sörensen, C. (2014) Stadtentwicklung und Klimaanpassung beispielhaft dargestellt am Einzugsgebiet der Wandse, TuTech Verlag, Hamburg.

IPCC (2012) Managing the Risks of Extreme Events and Disasters to Advance Climate Change Adaptation. A Special Report of Working Groups I and II Cambridge University Press, Cam, UK, and NY, USA.

Jacob, D. and Mahrenholz, P. (2006) REMO A1B scenario run. REMO climate of the 20th century run. UBA project, World Data Centre for Climate. CERA-DB: http://cera-www.dkrz.de/(accessed May 2011)

Jacob, D., Nilson, E., Tomassini, L., Bülow, K. (2009) REMO A1B scenario run. REMO climate of the 20th century run. BFG project. World Data Center for Climate (CERA-DB). http://cera-www.dkrz.de (accessed May 2011)

Pasche, E. (2003) Wasserbau - fünf Jahre: Alles fließt (River and Coastal Engineering - five years: everything flows); Department of River and Coastal Engineering, Technical University Hamburg Harburg; Schüthedruck GmbH, Hamburg.

Rottgardt, E., Schoetter, R., Kruse, E., Kunert, L., Schmidt, K., Stockinger, J., Verjans, E. (2014). Entwicklungsszenarien, Strategien und Anpassungsmaßnahmen. In: Kruse E., Zimmermann T., Kittel A., Dickhaut W. Knieling J., Sörensen C. Stadtentwicklung und Klimaanpassung-beispielhaft dargestellt am Einzugsgebiet der Wandse, Hamburg, TuTech Verlag, Hamburg, Germany.

Stovin, V.R., Moore, S.L., Wall, M., Ashley, R.M.(2013) The potential to retrofit sustainable drainage systems to address combined sewer overflow discharges in the Thames Tideway catchment. Water and Environment Journal, 27: $216-228$. doi: $10.1111 /$ j.1747-6593.2012.00353.

UN (2011) United Nations Department of Economic and Social Affairs. World Urbanization Prospects, the 2011 Revision. http://esa.un.org/unup/Documentation/Definition-Problems_1.htm (accessed 25 April 2014)

Velasco, M., Aldea, X., Nie, L., Baban, A. (2013). Deliverable D5.3.3 - Technical guidelines for redesign of storm water systems in a changing climate. Report number: PREPARED 2013.044.

Wong, T.H.F., Allen, R., Brown, R.R., Deletić, A., Gangadharan, L., Gernjak, W., Jakob, C., Johnstone, P., ReederM., Tapper, N., Vietz, G., Walsh, C.J. (2013) blueprint2013 - Stormwater Management in a Water Sensitive City, Cooperative Research Centre for Water Sensitive Cities, Australia.

Zhou, Q. (2014) A Review of Sustainable Urban Drainage Systems Considering the Climate Change and Urbanization Impacts. Water 2014, 6, 976-992.

Zoppou, C. (2001) Review of urban storm water models. Environmental Modelling \& Software, 16, $195-231$. 